\title{
Enantioselective Transport of $D, L$-Phenylalanine and $D, L$-Phenylglycine through a Bulk Liquid Membrane Containing Cinchona Alkaloid Derivatives as Chiral Selectors
}

\author{
S. Canepari, A.M. Girelli, * E. Mattei and D.Tosti \\ Dipartimento di Chimica, Sapienza Università di Roma, P. le A. Moro 5-00185 Roma, Italy
}

\begin{abstract}
Diversos derivados de Cinchona foram testados como carregadores quirais móveis, para o transporte enantiosseletivo de $D, L$-fenilglicina e $D, L$-fenilalanina, através de uma membrana líquida orgânica volumosa (MLV). Os efeitos de vários parâmetros, como natureza do carregador, concentrações do solvente na membrana, do tampão, do soluto e do carregador, no enriquecimento quiral da MLV, foram avaliados. Somente a $D, L$-fenilglicina foi sujeita, em certo grau, ao transporte enantiosseletivo; a razão máxima de enantiosseletividade (as taxas de transporte iniciais do enantiômero $L$ relativo ao antípoda) foi obtida empregando brometo de O-alil- $N$-(9-antracenilmetil) cinchonidínio como carregador. Em todos os casos, a seletividade mais alta foi observada durante os estágios iniciais do processo, indicando a taxa de aminoácido liberada da fase fonte (FF) para a fase orgânica da membrana (FM), como fator dirigente. O enriquecimento quiral pareceu depender mais de fatores termodinâmicos do que dos cinéticos, uma vez que a formação do complexo foi observada na interface (FF)/FM), enquanto a decomposição do complexo foi evidenciada na interface (FR)/(FM), onde FR é a fase receptora. $\mathrm{O}$ último fenômeno foi promovido pela presença de íons $\mathrm{H}^{+}$na FR.
\end{abstract}

Different cinchona derivatives were tested as chiral mobile carriers for enantioselective transport of $D, L$-phenylglycine and $D, L$-phenylalanine through a bulk organic liquid membrane (BLM). The effects of several parameters such as carrier nature, membrane solvent, buffer, solute and carrier concentrations on BLM enrichment were evaluated. Only $D, L$-phenylglycine is subjected to enantioselective transport at a certain degree; the maximum enantioselectivity ratio (the initial transport rates of the $L$-enantiomer relative to the antipode) was reached by employing O-allyl- $N$ (9-anthracenylmethyl)cinchonidinium bromide as carrier. In all cases the highest selectivity was observed during the initial stages of the process, indicating the rate of amino acid release from the source phase (SP) to the membrane organic phase (MP) as the driving factor. Chiral enrichment appeared to depend on thermodynamic factors more than on kinetic ones, since the complex formation was observed at (SP)/MP) interface, while complex decomposition was evidenced at (RP)/(MP) interface, where RP is receiving phase. The last phenomenon was promoted by $\mathrm{H}^{+}$ ions present in the RP.

Keywords: bulk liquid membrane, enantioselective transport, cinchona derivatives

\section{Introduction}

Industrial scale production of pure enantiomers may be achieved either by direct synthesis or by resolution of a racemic mixture. The last strategy is now the most popular mode as highlighted by the fact that $65 \%$ of all non natural enantiomeric drugs are made by resolution of racemic compounds.

The most used resolution methods are crystallisation and chromatography but both suffer from high capital

\footnotetext{
*e-mail: annamaria.gireli@unirma1i
}

costs. In the first method, high amounts of chiral reagent are requested, while in the second one, the dilution of the product requires a successive removal of solvent.

In the last few decades an increasing interest has been focused on the industrial scale applications of liquid-liquid extraction technologies for separative purposes. That is mainly due to the availability of hollow fibre membrane contactor devices. Those apparatuses achieve an efficient liquid-liquid mass transfer by passing the fluids on opposite sides through a microporous support without dispersion of one phase within another, and they offer a number of advantages over the conventional liquid/liquid extraction technique. ${ }^{1}$ In this 
context, two modules integrated membrane processes are of particular interest: in the first module the solution containing the mixture to be separated is the source phase in contact with the solution containing a selective carrier (membrane phase, MP), while in the second module the MP is in contact with the receiving solution. The analytes are carried from the source phase (SP) to the receiving phase (RP), which are generally both aqueous solutions, passing through the MP, which is immiscible with the other liquid phases. In this way, membrane phase remains stable and the separation may be accomplished by analytes concentration process. In addition, these techniques are suitable for a wide range of applications as a number of different carriers and solvents may be used..$^{2-6}$ The optimization of many experimental conditions (such as the choice of selective membrane solution and chemical composition of source and receiving phases) may be performed by very inexpensive and simple bulk liquid membrane (BLM) experiments, constituted by a U-shaped transport cell. In this case, a relatively thick layer of immiscible fluid is used to separate the source and receiving phases. There is no means of support for the membrane phase, that is kept apart from the external ones simply due to its immiscibility. Consequently, the transfer efficiency is usually very low (due to the small SP/MP and MP/RP contact surfaces), but the mass transfer processes are very similar to those occurring in contactor modules. Indeed, porous supports used to avoid dispersion of phases have been demonstrated to have no effect on partition coefficients. ${ }^{7}$

A recent development in liquid membranes is the insertion of a chiral carrier within the membrane phase, to favour the enantioselective transport of the analytes. ${ }^{8-11}$

Since this discovery, membrane contactors became a very promising technology, easily transferable from laboratory to industrial scale, even though a further effort has to be focused on new selective carriers. In a previous work, the use of cinchonidine for enantiomeric enrichment of phenylalanine and phenylglycine has been investigated. ${ }^{12}$ The obtained results have encouraged further investigation on using cinchona derivatives as carriers.

Cinchona alkaloids are commercially available and represent an interesting group of organic compounds, widely used as resolving agents for chiral acids, ${ }^{13} \mathrm{~N}$-derivatized amino acid ${ }^{14}$ binaphtols,${ }^{15}$ oligopeptides. ${ }^{16}$ Structurally, they consist of a planar quinoline and rigid quinuclidine rings, which are connected by a secondary methyl alcohol bridge. Conformational flexibility is available only for the torsions of $\mathrm{C}_{8}-\mathrm{C}_{9}$ and $\mathrm{C}_{9}-\mathrm{C}_{4}$ bonds (see Figure 1). As a whole, these molecules could be viewed as semi rigid frameworks, which make them promising as chiral carriers in liquid membrane transport. The arrangements of the five stereogenic centres within the cinchonine and cinchonidine molecules (at position 1, 3, 4, 8, 9) might provide an excellent basis for effective chiral recognition. Cinchonine and cinchonidine have N1, C3, C4 with identical configuration $(1 S, 3 R$, $4 S$ ) while $\mathrm{C} 8 / \mathrm{C} 9$ have opposite configurations. Although they are diastereomers, they are often termed "pseudoenantiomers" as it is observed that the configuration of C8/ C9 is predominantly responsible for molecular recognition of chiral compounds. ${ }^{17,18}$

In this paper, we report the results of the enantioselective transport of $D, L$-phenylglycine and $D, L$-phenylalanine across a bulk liquid chloroform membrane by means of different commercial cinchona derivatives as carriers, selected in order to study the influence of their structure and nature on enantioselective transport ability. Some quaternary ammonium salts (selectors 4-7) have been included among the investigated cinchona alkaloids, in order to evaluate the contribution of ion-pair interaction in the analyte-carrier complex formation, which is supposed to be predominant over the other interactions. In addition, they are "tuned" with various electronwithdrawing groups, in order to enhance their positive charge and possibly even to provide additional steric enhancement. So quinine (selector 1), cinchonidine (2), hydroquinidine-3,4-methyl2-quinolyl ether (3), $\mathrm{N}$-benzylcinchonidinium bromide (4), $O$-allyl- $N$-(9-anthracenylmethyl)cinchonidinium bromide (5), $N$-(4-trifluoromethylbenzyl)cinchonidinium bromide (6), $N$-(9-anthracenylmethyl)cinchonidinium chloride (7) are examined. Moreover, the influence of membrane solvent nature on the enantiotransport of $D, L$ phenylglicine is investigated, employing some dichloro organic solvents, like dichloromethane, 1,2-dichloroethane and 1,4-dichlorobutane.

\section{Experimental}

\section{Reagents}

$D, L$-phenylglycine, $D, L$-phenylalanine and all the chiral selectors: quinine, cinchonidine, hydroquinidine-3,4methyl-2-quinolyl ether, $N$-benzylcinchonidinium bromide, $O$-allyl- $N$-(9-anthracenylmethyl)cinchonidinium bromide, $\mathrm{N}$-(4-trifluoromethylbenzyl)cinchonidinium bromide, $N$-(9anthracenylmethyl)cinchonidium chloride are purchased from Aldrich, Milan, Italy. Solvents of HPLC grade and sodium phosphate salts are from Sigma, Milan, Italy.

\section{Chromatographic system}

The chromatograms of aqueous solution are recorded on a HPLC Kontron system, consisting of: a model 422 pump and a UV-Visible 432 detector, complete with 
<smiles>C=C[C@H]1CN2CC[C@H]1[C@H]2[C@H](O)c1ccnc2ccc(OC)cc12</smiles>

Quinine (selector 1)

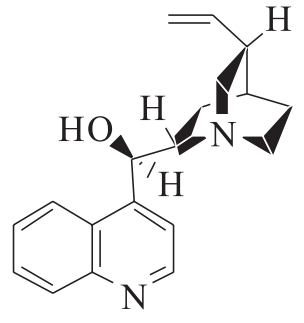

Cinchonidine (selector 2)<smiles></smiles>

Hydroquinidine -3,4-methyl2- quinolyl ether<smiles>C=C[C@H]1C[C@H]2CC[N+]1(Cc1ccccc1)[C@H]2[C@H](O)c1ccnc2ccccc12</smiles>

$N$-benzylcinchonidinium bromide (selector 4 )<smiles>C=CCO[C@H](c1ccnc2ccccc12)[C@@H]1[C@H](C=C)CC[N+]12Cc1ccccc1-c1ccccc12</smiles>

$O$-allyl- $N$-(9-anthracenylmethyl) cinchonidinium bromide (selector 5)<smiles>C=CC1C[C@H]2CC[N@+]1(Cc1ccc(C(F)(F)F)cc1)[C@H]2[C@H](O)c1ccnc2ccccc12</smiles>

$N$-4(trifluoromethylbenzyl) cinchonidinium bromide (selector 6)

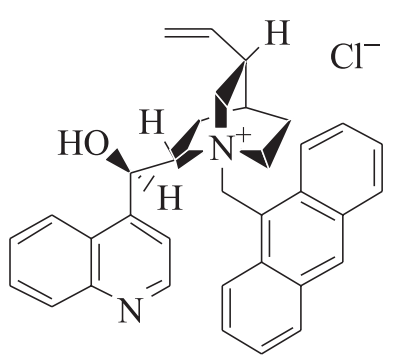

$N$-(9-anthracenylmethyl) cinchonidinium chloride (selector 7)

Figure 1. Structure of cinchona alkaloids employed as carriers.

a Rheodyne 7125 injector with a $20 \mu \mathrm{L}$ sample loop (Rheodyne, Berkeley, CA, USA); a Chirobiotic T filled with a $10 \mu \mathrm{m}$ Teicoplanine phase $(250 \mathrm{~mm}$ length, $4.6 \mathrm{~mm}$ i.d.) from Astec. The mobile phases were $7.7 \mathrm{mmol} \mathrm{L}^{-1}$ triethylamine/acetate (TEAA) buffer solution at $\mathrm{pH} 4.5$ for $D, L$-phenylglycine resolution and an ethanol: water mixture $(60: 40, \mathrm{v} / \mathrm{v})$ containing $1.4 \mathrm{mmol} \mathrm{L}^{-1}$ of acetic acid for $D, L$-phenylalanine. Flow rate was $1 \mathrm{~mL} \mathrm{~min}^{-1}$ in both cases. Aliquots of $20 \mu \mathrm{L}$ of sample are measured each time. Absorbance values of the effluent monitored at $254 \mathrm{~nm}$ and $220 \mathrm{~nm}$ for $D, L$-phenylglycine and $D, L$-phenylalanine, respectively, are recorded by an integrator system consisting of a PC equipped with an Intel processor, Pentium III 800 $\mathrm{MHz} \mathrm{CPU}$, and Agilent ChemStation software for LC version A.08.03 (847) running under MS Windows NT 4.00.31 OS.

\section{Procedure for the enantioselective transport}

This study was carried out applying the bulk liquid membrane (BLM) technique using six " $U$ " glass membranes (i.d. $25 \mathrm{~mm}$; height of each arm $6 \mathrm{~cm}$ ), properly designed and always working in parallel. In this way, the dependence on temperature in each series of experiments may be neglected. Membrane phases were stirred at a same constant rate by a magnetic 15 place multi-stirrer (VELP Scientifica, Italy).

Source phases containing the racemic $10 \mathrm{mmol} \mathrm{L}^{-1}$ $D, L$-amino acid mixture and the receiving phase are in phosphate buffer, at different $\mathrm{pH}$ and concentration depending on the examined carrier. In the case of cationic carriers: ( $N$-benzylcinchonidinium bromide, $O$-allyl- $N$ (9-anthracenylmethyl)cinchonidinium bromide, $N$-(4trifluoromethylbenzyl)cinchonidinium bromide, $N$-(9anthracenylmethyl)cinchonidinium chloride) an alkaline source phase ( $\mathrm{pH} 11)$ is employed, while the receiving phase is maintained at $\mathrm{pH} \mathrm{3}$, so that the protonation mechanism of amino acid allows an efficient release of the enantiomer at the membrane/receiving interface. In the case of neutral carriers, SP is maintained close to the isoelectric point of the corresponding amino acid, which represents the value of their highest solubility in apolar membrane solvents, while the receiving phase $\mathrm{pH}$ is fixed to 7 . These optimal $\mathrm{pH}$ values were obtained in our precedent study 
about $D, L$-phenylglycine and $D, L$-phenylalanine transport across a membrane phase containing cinchonidine as a carrier. $^{12}$

The effect of phosphate concentration in the range $10-100 \mathrm{mmol} \mathrm{L}^{-1}$ is investigated. Membrane phases are prepared dissolving the carriers in $20 \mathrm{~mL}$ of water-insoluble organic solvents. Different carrier concentrations and organic solvents nature are investigated.

In all cases, the amino acid transport across a membrane phase in the absence of carrier is checked, always obtaining a negligible transport compared to the facilitated one.

\section{Results and Discussion}

In each experiment, $60 \mu \mathrm{L}$ samples were withdrawn from the aqueous source and the receiving phases at fixed intervals, in order to allow the determination of transported enantiomers amount. The data collected from each experiment were treated as previously reported. ${ }^{12}$

\section{Influence of buffer concentration}

The effect of buffer concentration on $D, L$-phenylglycine facilitated transport is investigated on two systems that use a neutral carrier (selector $\mathbf{1}$ ) and a ionic one (selector $\mathbf{6}$ ). The phosphate buffer concentrations of both source and receiving phases are varied in the range $10-100 \mathrm{mmol} \mathrm{L}^{-1}$. In order to avoid the presence of a concentration gradient, the same initial concentration is always employed in source and receiving solutions. Concentrations below $10 \mathrm{mmol} \mathrm{L}^{-1}$ are excluded, because of their low buffering capacity, while values over $100 \mathrm{mmol} \mathrm{L}^{-1}$ are not considered as they caused a loss in enantioselectivity. Results reported in Figure 2 are shown in terms of $\mathrm{J} / \mathrm{J}_{\max } \%$ ratio, where $\mathrm{J}$ is the enantiomeric flux and $\mathrm{J}_{\max }$ its maximum value in the considered series of experiments. The increase of phosphate concentration leads to an increase of transport across the membranes in all the examined systems. This is probably due to the increase of ionic strength, which influences the solubility and amino acid solvation. A different effect on the enantioselectivity is instead observed for the two membrane systems. As shown in Figure 2, neutral carrier (selector 1) gives no enantiomeric enrichment in the whole explored range, while the quaternary ammonium salt (selector 6) shows a decrease of the enantioselectivity with the increase of buffer concentration. This is probably due to the counter transport mechanism of phosphate ions, whose relevance, increasing with [phosphate], influences the complexation/ decomplexation mechanism of ion pair diastereomeric adducts without showing selectivity.

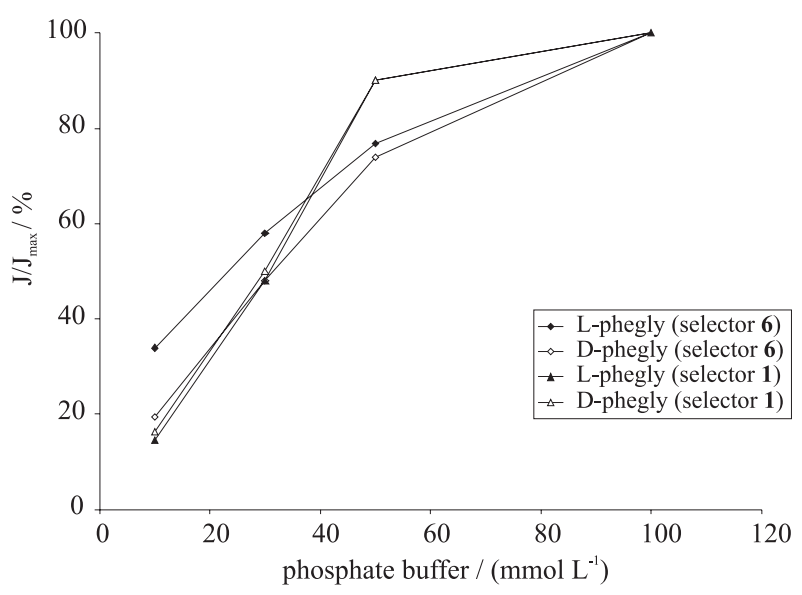

Figure 2. Normalized initial flux $\left(\mathrm{J} / \mathrm{J}_{\max }\right)$ of $10 \mathrm{mmol} \mathrm{L}^{-1} D, L$-phenylglycine (phegly) with quinine (selector 1) and $N$-(4-trifluoromethylbenzyl) cinchonidinium bromide (selector 6 ) as carriers at various phosphate buffer concentration. The source and receiving phases were at $\mathrm{pH}$ indicated in experimental section. The organic phase was constituted of $30 \mathrm{mmol} \mathrm{L}^{-1}$ carrier in chloroform.

\section{Influence of carrier concentration}

The effect of carrier concentration in the membrane phase is studied for all the examined systems on both transport rate and enantioselectivity of $D, L$-phenylglycine. Figure 3 shows, with the only exception of selector 7 , that transport rate tends to increase with the carrier concentration. In the case of selector $\mathbf{7}$, a slight decrease of transport rate is observed with the increase of concentration. This effect is probably due to a decrease in the diffusion coefficients of the complex in the MP. In fact, an increase of MP viscosity is qualitatively observed at [selector 7] $>20 \mathrm{mmol} \mathrm{L}^{-1}$. Furthermore cationic carriers produce higher transport rates than the neutral ones, as expected. The only exception is selector $\mathbf{5}$ that furnishes very low transport rates due to its higher steric hindrance, which reflects in a weaker interaction with the analyte. This topic will be discussed in detail in the following sections. Regarding the enantioselectivity (Figure 4), a behaviour depending on chiral selector nature is evidenced. In the case of the three cationic carriers (selectors $5,6,7$ ), $\alpha$ ratio expressed as $\mathrm{J}_{\mathrm{L}} / \mathrm{J}_{\mathrm{D}}$, increases with the increase of [carrier]. Selector $\mathbf{5}$ shows the highest value $\left(\alpha=2\right.$ at $\left[\right.$ carrier] $\left.=20 \mathrm{mmol} \mathrm{L}^{-1}\right)$ confirming the importance of a steric interaction for the discriminatory process. In the case of neutral carriers, cinchonidine and quinine present enantiomeric ratio invariably lower than 1 , while selectors $\mathbf{3}$ and $\mathbf{4}$ do not provide any enantioselectivity.

\section{Influence of membrane solvent}

Membrane solvent properties influence formation and diffusion of diastereomeric complexes and a remarkable 


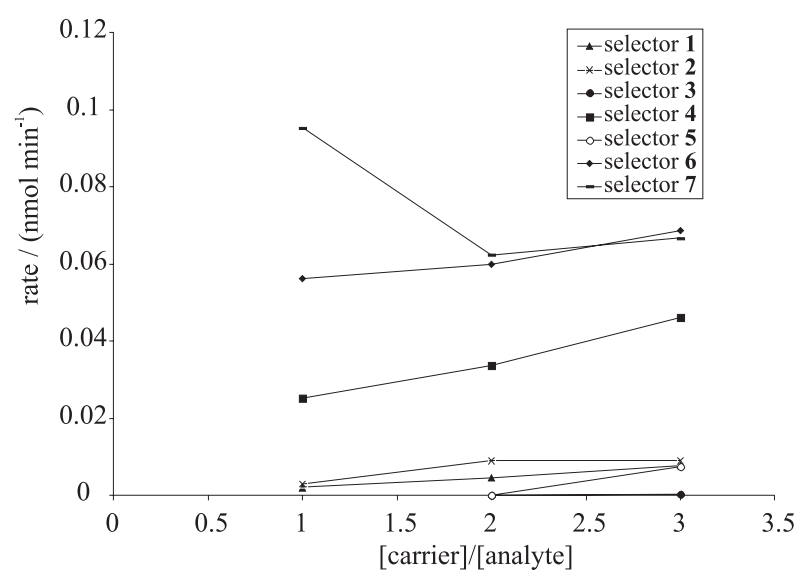

Figure 3. Figure 3. Effect of [carrier]/[analyte] ratio on L-phenylglycine transport rate. Carriers: quinine (selector $\mathbf{1}$ ), cinchonidine (selector 2 ), hydroquinidine3,4-methyl-2-quinolyl ether (selector 3), $\mathrm{N}$-benzylcinchonidinium bromide (selector 4), $O$-allyl- $N$-(9-anthracenylmethyl)cinchonidinium bromide (selector 5), $\mathrm{N}$-(4-(trifluoromethylbenzyl)cinchonidinium bromide (selector 6), $\mathrm{N}$-(9-anthracenylmethyl)cinchonidinium chloride (selector 7). The source and receiving phases were at $\mathrm{pH}$ indicated in experimental section.

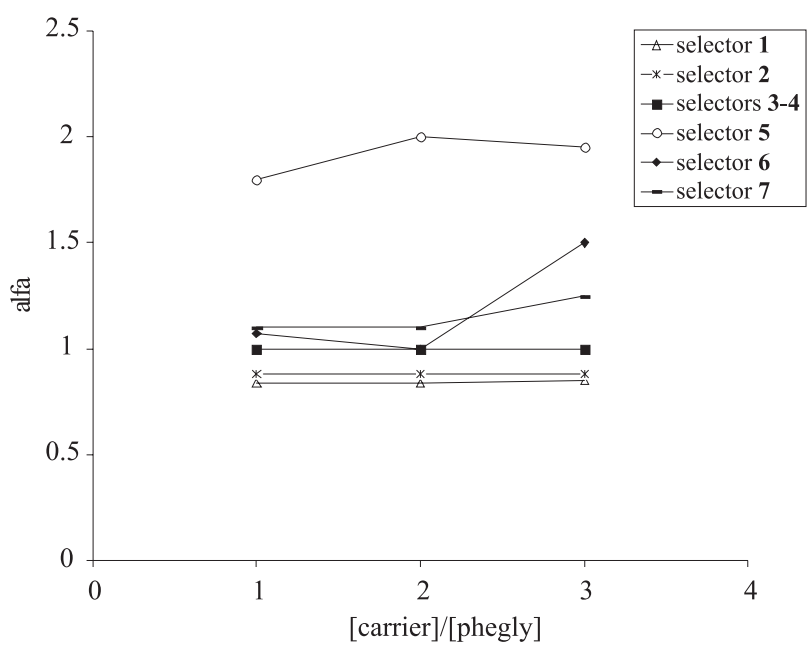

Figure 4. Enantioselectivity ratios $(\alpha)$ of $10 \mathrm{mmol} \mathrm{L}^{-1} D, L$-phenylglycine at different initial concentration [carrier]/[analyte] ratios. The source and receiving phases were $10 \mathrm{mmol} \mathrm{L}^{-1}$ phosphate buffer aqueous solution at $\mathrm{pH}$ indicated in experimental section. The organic phase was prepared in chloroform. Carriers: quinine (selector 1), cinchonidine (selector 2), hydroquinidine-3,4-methyl-2-quinolyl ether (selector 3), $N$-benzylcinchonidinium bromide (selector 4), $O$-allyl- $N$-(9-anthracenylmethyl)cinchonidinium bromide (selector 5), $\mathrm{N}$-(4-trifluoromethylbenzyl)cinchonidinium bromide (selector 6), $\mathrm{N}$-(9anthracenylmethyl)cinchonidinium chloride (selector 7).

influence on transport efficiency and selectivity is then expected. To put into evidence these effects, a study on $D, L$-phenylglycine transport across a membrane in various chloroform/dichlorurate mixtures is undertaken. Dichloromethane, 1,2-dichloroethane and 1,4-dichlorobutane are mixed with chloroform at ratio $90 / 10(\mathrm{v} / \mathrm{v})$. The addition of chloroform is necessary to reach a sufficient solubility of the carrier. In these experiments, $O$-allyl- $N$-(9-anthracenylmethyl) cinchonidinium bromide was chosen as carrier, since it was the most selective carrier. In Table 1 some chemical properties of the pure examined solvents are resumed and in Figure $5 \alpha$ values (left axis) and $\mathrm{J} / \mathrm{J}_{\max } \%$ values (right axis) as a function of solvent polarity (expressed as dipolar moment) are reported. Regarding the effect of solvent polarity on the flux of the single enantiomer, a non-linear trend appeared, indicating that different processes are implicated and that they are differently influenced by this parameter. Anyway, in the working conditions, the adduct dissociation at the MP/ $\mathrm{RP}$ interfaces is strongly favoured, ${ }^{19}$ so the mass transport efficiency is mainly influenced by the adduct formation at the SP/MP interface and by the diffusion coefficient in the membrane phase. It is well-known that adduct formation process is mainly dependent on the strength of analyte-carrier interaction, so that the solvents with a low dipolar moment favour the analyte-carrier ion pair interaction, but present scarce efficiency in the solvation of the formed adduct. On the contrary, a high dipolar moment of the solvent provides a good efficient adduct solvation, but hampers ionic and dipolar analyte-carrier interactions. In relation of the adduct diffusion coefficient, it is highly dependent on the membrane viscosity and again on the solvation sphere. Thus, the maxima transport rate values for both the enantiomers are shown by the solvents with the lower viscosity: dichloromethane and chloroform. Dipolar moment influences the adduct formation and regulates enantioselectivity, as evidenced in Figure 5 by the linear decrease of $\alpha$ as a function of the pure solvent dipolar moment shown.

Table 1. Chemical properties of the pure examined solvents

\begin{tabular}{lccc}
\hline Solvent & $\begin{array}{c}\text { Dipolar Moment / } \\
\text { Debye }^{\mathrm{a}}\end{array}$ & $\begin{array}{c}\text { Viscosity / } \\
\left(\mathrm{mPa} \mathrm{s} 25^{\circ} \mathrm{C}\right)^{\mathrm{a}}\end{array}$ & $\begin{array}{c}\text { Dielectric } \\
\text { Constant }^{\mathrm{a}}\end{array}$ \\
\hline Chloroform & 1.04 & 0.537 & 4.8 \\
1,4-dichlorobutane & 1.60 & 1.988 & 8.9 \\
1,2-dichloroethane & 1.75 & 0.779 & 10.6 \\
Dichloromethane & 2.22 & 0.413 & 10.7 \\
\hline
\end{tabular}

aData taken from Handbook of Chemistry and Physics CRC, $52^{\text {nd }}$ ed., 1971, p.72.

\section{Enantioselective process of phenylglycine}

The study was performed at the optimal conditions previously determined: chloroform as membrane solvent; phosphate buffer $10 \mathrm{mmol} \mathrm{L}^{-1}$ and carrier concentration $30 \mathrm{mmol} \mathrm{L}^{-1}$. Selectors 5, 6, 7, which showed an enantioselective transport towards the $D, L$-phenylglycine were employed.

In Figure 6 it is reported the time pattern of percentage mass distribution of $D$ - and $L$ - phenylglycine in the source, receiving and membrane phases in the presence 


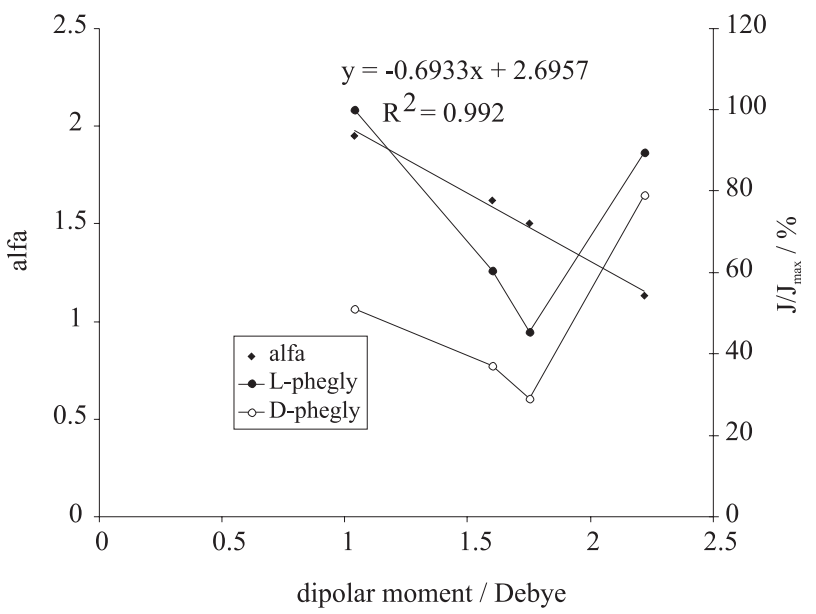

Figure 5. Effect of membrane solvent polarity, expressed as dipolar moment, on enantioselectivity ratios $(\alpha)$ and $\%$ normalized initial fluxes $\left(\mathrm{J} / \mathrm{J}_{\max }\right)$ of $10 \mathrm{mmol} \mathrm{L}^{-1} \mathrm{D}, L$-phenylglycine (phegly). The organic phase was constituted of $30 \mathrm{mmol} \mathrm{L}^{-1} \mathrm{O}$-allyl- $\mathrm{N}$-(9-anthracenylmethyl) cinchonidinium bromide (selector $\mathbf{5}$ ) in chloroform alone and in mixture with some dichlorurate solvents (1,4-dichlorobutane, 1,2-dichloroethane, dichloromethane) at ratio $10 / 90(\mathrm{v} / \mathrm{v})$.

of selector 5. Membrane phase concentrations were determined by the difference from measured ones in the source and in the receiving phases. In the first $200 \mathrm{~min}$ the amount of the enantiomers in the receiving phase linearly increases, while it decreases in the source phase. The $L$-enantiomer was faster transferred from the source to the membrane phase, indicating that its structure is more suitable to the interaction with the carrier, and consequently this species is more enriched in the receiving phase. This fact clearly indicates that the rate determining step is the transfer of the enantiomer at the interface between source and chloroform phases. The amount of amino acid in the membrane phase revealed that at the beginning the transport rate at the interface SP-MP is higher than that at the interface (MP)/(RP), later they were inverted probably because of the $L$-species decrease in the source phase.

Successively, in order to characterize the enantioselective capability of the carriers, the enantiomeric excesses (ee) were determined. They were expressed in percent as:

$e e \%=\frac{[\mathrm{L}] \mathrm{r}-[\mathrm{D}] \mathrm{r}}{[\mathrm{D}] \mathrm{r}+[\mathrm{L}] \mathrm{r}} \times 100$

where $[D]_{\mathrm{r}}$ and $[L]_{\mathrm{r}}$ were the amount of $D$ - and $L$ enantiomers in the receiving phase at a fixed time. The obtained data are reported in Figure 7 and so it appears that the greatest enantio-enrichment is present in the early stages, but the entire system will finally come to an equilibrium with an essentially racemic mixture of solute in aqueous phases. The carrier $O$-allyl- $N$-(9-antracenylmethyl) cinchonidinium presented higher ee value (38\%) than the other two selectors.

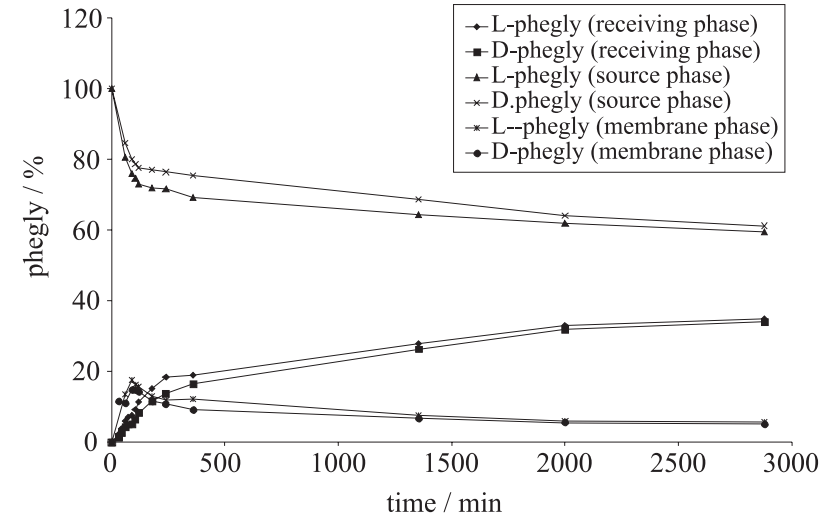

Figure 6. Amount (nmol \%) of $D$ - and $L$-phenylglycine (phegly) present in the three different phases during the transport experiment across chloroform membrane containing selector $\mathbf{6}$ as carrier. Conditions: $\mathrm{pH}_{\text {source }} 11 ; \mathrm{pH}_{\text {rec }} 3$; [phosphate buffer] $=10 \mathrm{mmol} \mathrm{L}^{-1}$; [selector 6]/ [phenylglycine] $=3$.

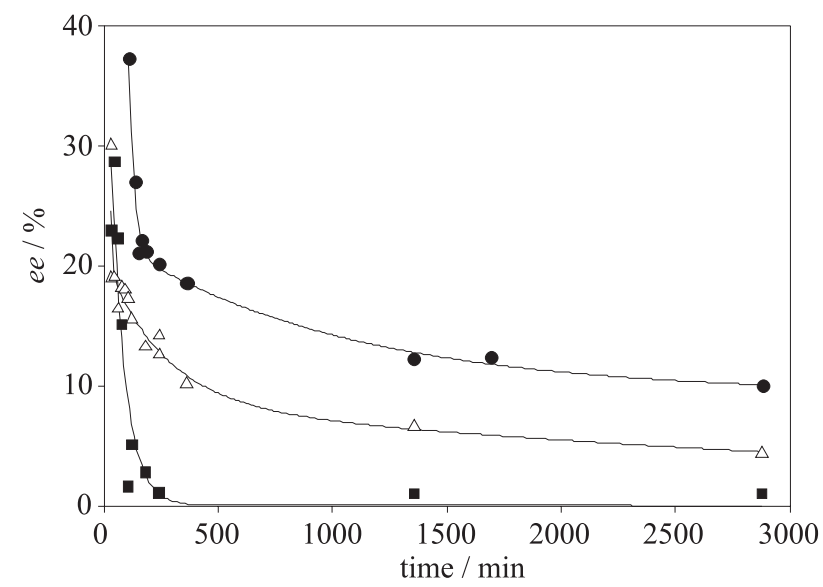

Figure 7. Comparison of the enantiomeric excess (ee\%) for the $D, L$ phenylglycine at the receiving phase with the carriers: $(\bullet) O$-allyl$N$-(9-anthracenylmethyl)cinchonidinium bromide (selector 5), $(\triangle$ ) $N$-(4-trifluoromethylbenzyl)cinchonidinium bromide (selector 6), (ם) $N$-(9-anthracenylmethyl)cinchonidinium bromide (selector 7).

\section{Influence of carrier nature}

Transport rates of phenylalanine and phenylglycine in the presence of each carrier were evaluated as the initial slopes of nmol vs. time plots. To avoid the influence of external parameters ( $\mathrm{T}$, stirring, etc), all the experiments were carried out in parallel. In Table 2, the obtained data are reported together with the relative $\alpha$ values.

A scrutiny of Table 2 reveals that the transport rates are always greater for phenylalanine than for phenylglycine, while enantioselectivity values show an opposite behaviour. These results show that the methylene group between the aromatic ring and the asymmetric carbon present in phenylalanine, hindered the stereochemical interactions needed for chiral recognition, even if the dominating ion pairing interaction is permitted. 
Table 2. Transport rates of $L$-amino acids and enantioseparation $(\alpha)$ values of $D, L$-phenylglycine and $D, L$-phenylalanine determined for different cinchona alkaloid carriers

\begin{tabular}{|c|c|c|c|c|}
\hline \multirow[t]{2}{*}{ Carriers } & \multicolumn{2}{|c|}{ Transport Rates / (nmol min $\left.{ }^{-1}\right)$} & \multicolumn{2}{|c|}{$\alpha^{a}$} \\
\hline & $L$-phenylglycine & $L$-phenylalanine & $D, L$-phenylglycine & $D, L$-phenylalanine \\
\hline Cinchonidine $^{8}$ & - & - & 0.9 & 1.0 \\
\hline Quinine & 0.0014 & 0.0040 & 0.9 & 1.0 \\
\hline Hydroquinidine-3,4-methyl-2-quinolyl ether & 0.0005 & 0.0007 & 1.0 & 1.0 \\
\hline$N$-9-(anthracenylmethyl) cinchonidinium chloride & 0.0486 & 0.0989 & 1.2 & 1.0 \\
\hline$O$-allyl- $N$-9-(anthracenylmethyl) cinchonidinium bromide & 0.0065 & 0.0116 & 2.0 & 1.0 \\
\hline $\mathrm{N}$-benzylcinchonidinium bromide & 0.0131 & 0.0563 & 1.0 & 1.0 \\
\hline$N$-4-(trifluoromethylbenzyl) cinchonidinium bromide & 0.0562 & 0.1305 & 1.6 & 1.0 \\
\hline
\end{tabular}

${ }^{\mathrm{a}} \alpha=$ initial rates of transport of the $L$-enantiomer relative to the antipode.

Moreover, the lesser polarity of phenylalanine respect to phenylglycine, increases its affinity towards the membrane phase, reducing thus the enantioselectivity at the (SP)/ (MP) interface.

A certain influence of the carrier structure on transport rates and enantioselectivity is also highlighted. The obtained data strongly suggest that in the transport processes, ionic interaction is the driving force for prime molecular association, but the hydrogen bound also plays an important role in the carrier/analyte complex formation. These findings explain the lowest transport rate for hydroquinidine-3,4-methyl-2-quinolyl ether (selector 3), which has neither a quaternary ammonium ion nor the hydroxylic group available, and the enhanced transport rates for the selectors $\mathbf{4 , 6}$ and $\mathbf{7}$, which present free $-\mathrm{OH}$ at $\mathrm{C}-9$ in the quinine moiety. The involvement of hydrogen bond also in the stereodiscrimination process is evidenced by the opposite transport order of $D$ - and $L$-phenylglycine observed in the presence of cinchonidinium bromide salt (selector 6) and of cinchonidine and quinine (selectors 1, 2). This is indeed in agreement with the different C8/C9 stereochemistry of the carriers. A further proof is obtained by the behaviour of selector $\mathbf{3}$, which differs from quinine and cinchonidine for the presence of an ethyl group and is devoid of hydrogen-donating properties at the chiral centre $\mathrm{C}$, so it does not give any enantiomeric enrichment. Furthermore, as previously reported, the loss of the hydroxylic group in the chiral selector also gives rise to a significant decrease in the amino acids transport rates. On the basis of all the above discussed experimental observations, a reasonable chiral discrimination mechanism may be tentatively proposed, to account for the different interactions between the chiral carriers and the two antipodes of the phenylglycine. Such a mechanism takes into account the following interactions: (i) hydrogen bond between the amino group of the amino acid and the $-\mathrm{OH}$ at $\mathrm{C} 9$ of the quinine moiety; (ii) $\pi-\pi$ interaction between the two aromatic systems of amino acid and quinoline ring; (iii) ion pair interaction between the positively charged quinuclidine nitrogen and the negatively charged carboxylic group of the amino acid. In addition, the presence of an electronwithdrawing substituent, like $p-\mathrm{CF}_{3}$, on $N$-benzyl group (selector 6) enhances the ion pairing interactions and consequently the carrier is more selective with respect to the non substituted compound (Figure 8). Therefore, following this hypothesis, the $L$-phenylglycine interacts with chiral carriers containing an asymmetric carbon $9 S$ in a stronger manner than the $D$-enantiomer, so the former is firstly transported in the receiving phase.

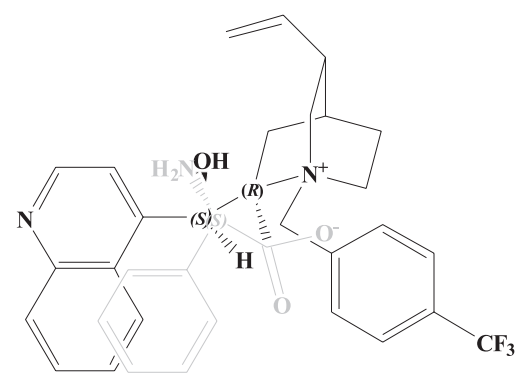

Figure 8. Proposed chiral recognition model: possible interactions between $L$-phenylglycine and $N$-(4-trifluoromethylbenzyl)cinchonidinium bromide.

An anomalous behaviour is obtained for the carriers containing the 9-anthracenyl group. In these cases, two facts may be evidenced: (i) the transport rate order is opposite respect to the cinchonidine one, even though they present the same C8/C9 stereochemistry and (ii) the enantioselectivity of selector $\mathbf{5}$ is higher, even though it has a derivatized hydroxyl group at C9. Both findings imply that the presence of the 9-anthracenyl group, whose spatial position is fixed for steric reasons, causes a modified chiral recognition pattern. In these cases, the further presence of an allyl substituent 
on the secondary hydroxyl group, may contribute to the stereoselective interactions, enhancing steric hindrance, in agreement to the data reported by Corey. ${ }^{20}$

\section{Conclusions}

Cinchona alkaloids, which have been already used to prepare chiral stationary phases for chromatographic resolution of racemates, were employed as carriers in bulk liquid membrane systems. Conditions for improving the release efficiency of the enantiomers into the receiving phase were examined and some of the parameters influencing the transport rate and the enantioselectivity of the process were identified.

Regarding the amino acid transport, an important factor appears to be its lipophilicity, i.e. its availability at the interface between the source and membrane phases.

Regarding the enantioselectivity, the presence of a methylene group in phenylalanine causes a loss of stereoselective contacts between the molecular surfaces of selector and enantiomer. As a consequence, the enantiodiscriminatory power of phenylalanine is lower than the phenylglicine one.

Regarding the carriers, $O$-allyl- $N$-(9-anthracenylmethyl) cinchonidinium bromide presents the highest enantioselectivity, due to its enhanced capacity to discriminate the enantiomers by steric hindrance. The enantiomeric excess of $38 \%$ obtained by BLM (after one single stage of contact) with this carrier could be considered a rather good result, but to achieve an effective separation of the two enantiomers a multistep contact process could be performed by recirculating the source and the organic phases through hollow fibers modules.

\section{References}

1. Gabelman, A., Hwang, S. T.; J. Membr. Sci. 1999, 159, 61.

2. Misra, G. In Chemical Separations with Liquid Membranes; Bartsch, R. A.; Way, J. D., eds.; ACS Symposium Series 642, ACS: Washington, DC, 1996; ch. 25.
3. Satinder, A., ed.; Chiral Separation: Application and Technology, ACS: Washington DC, 1993.

4. Tsukube, H.; J. Coord. Chem. 1987, 16, 101.

5. Noble, R. D.; Way, J. D., eds; Liquid Membranes: Theory and Applications, ACS: Washington DC, 1987.

6. Sastre, A. M.; Kumar, A.; Shukla, J. P.; Singh, R. K.; Sep. Purif. Methods 1998, 27, 213.

7. Schlosser, S.; Kertesz, R.; Martak, J.; Sep. Purif. Technol. 2005, $41,237$.

8. Jlao, F.; Chen, X.; Hu, W.; Yang, L.; Huang, K.; J. Braz. Chem. Soc. 2007, 18, 804.

9. Demirel, N.; Bulut, Y.; Hosgoren, H. E.; Chirality 2004, 16, 347.

10. Baragan, B.; Blackburn, A. G.; Breccia, P.; Davis, A. P.; De Mendoza, J.; Padron Carrillo, J. M.; Prados, P.; Riedner, J.; De Vries, J. G.; Chem. Eur. J. 2002, 8, 2031.

11. Ma, M.; Chen, B.; Luo, X. B.; Tan, H.; He, D. S.; Xie, Q. I.; Yaop, S. Z.; J. Membr. Sci. 2004, 234, 101.

12. Stella., D.; Calzado, J. A.; Girelli, A. M.; Canepari, S.; Bucci, R.; Palet, C.; Valiente, M.; J. Sep. Sci. 2002, 25, 229.

13. Mandl, A.; Nicoletti, L.; Lammerhofer, M.; Linder, W.; J. Chromatogr., A 1999, 858, 1.

14. Pilar, F.; Blanc, J.; Oberleitner, W. R.; Maier, N. M.; Lindler, W.; Minguillon, C.; Anal. Chem. 2002, 74, 4175.

15. Rosini, C.; Altemura, P.; Pini, D.; Bertolucci, C.; Zullino, G.; Salvatori, P.; J. Chromatogr., A 1985, 348, 79.

16. Czerwenka, C.; Lammerhofer, M.; Maier, N. M.; Rissanen, K.; Linder, W.; Anal. Chem. 2002, 74, 5658.

17. Dijkstra, D. H.; Kellogg, R. M.; Wynberg, H.; Svendsen, J. S.; Marko, I.; Sharpless, K.B.; J. Am. Chem. Soc. 1989, 111, 8069.

18. Maier, M.; Nicoletti, L.; Lammerhofer, M.; Lindner, W.; Chirality 1998, 11, 522.

19. Brice, J.; Pirkle, W. H. In Chiral Separations: Applications and Technology; Ahuja, S., ed., ACS: Washington DC, 1993, ch. 11.

20. Corey, J.; Xu, F.; Noe, M. C.; J. Am. Chem. Soc. 1997, 19, 12414.

Received: March 28, 2008

Web Release Date: January 22, 2009 